\title{
ASSIS, J. M. Machado de. Badaladas Dr. Semana. Organização, apresentação, notas e índice onomástico por Sílvia Maria Azevedo. São Paulo: Nankin, 2019. 2 t.
}

\section{GRANJA, Lúcia. Machado de Assis - antes do livro, o jornal: suporte, mídia e ficção. São Paulo: Ed. Unesp, 2018.}

\author{
Alvaro Santos Simões Junior \\ Universidade Estadual Paulista - Campus Assis, Assis, São Paulo / Brasil \\ alvaro.simoes@unesp.br
}

http://orcid.org/0000-0002-5269-7108

Em texto de palestra que já conta 52 anos, Antonio Candido apontou como diferencial da obra dos "grandes escritores" a "polivalência do verbo literário", a qual propicia a "cada grupo e cada época" nela encontrar satisfação para suas “obsessões" e "necessidades de expressão" (CANDIDO, 1977, p. 18). Essa generalização era formulada como preâmbulo para que o crítico pudesse tratar, diante de uma plateia de norte-americanos, dos diferentes aspectos de Machado de Assis descobertos por "sucessivas gerações de leitores e críticos brasileiros” (CANDIDO, 1977, p. 18).

Como um dos clássicos da literatura de língua portuguesa, Machado de Assis segue, com efeito, fascinando e desafiando a perspicácia de leitores e críticos em todo o mundo. Algumas publicações recentes fazem pensar que "o Machado da atual geração" é o disciplinado, prolífico e fundamentalmente criativo colaborador da imprensa periódica.

A publicação machadiana recente mais notável é, sem dúvida, a recolha das crônicas intituladas Badaladas, originalmente publicadas na Semana Ilustrada, de 1869 a 1876, com a assinatura do Dr. Semana. Havia muito especulava-se sobre a autoria dessa série de crônicas e especialistas como Galante de Sousa e Raimundo Magalhães Jr. chegaram a considerar a possibilidade de Machado de Assis ser o responsável por ela. Sílvia 
Maria Azevedo afastou as dúvidas, transcreveu os textos, atualizando a sua ortografia, e distribuiu-os pelas mais de 1.600 páginas de dois grandes volumes prudentemente acondicionados em uma caixa de proteção. O projeto editorial da editora Nankin, de São Paulo, é notável, entre outros aspectos, pela recuperação das ilustrações que acompanhavam originalmente as Badaladas, isto é, o clichê de abertura, em que, por detrás de um listel onde se via o título da seção, se colocavam as personagens Moleque, garoto negro, e Dr. Semana, empunhando uma sineta. Entre cada fragmento dos textos, reproduz-se, como se fazia no periódico, a sineta, inclinada ora para a esquerda, ora para a direita, de modo a indicar o seu uso. Cada ano de publicação é anunciado, no livro, por uma página marmorizada. Ao final de cada volume, encontra-se o índice onomástico correspondente aos anos nele enfeixados.

Sílvia Azevedo apurou a autoria das crônicas ao analisar marcas externas e internas. As externas dizem respeito à biografia do autor e ao restante de sua obra, que foi confrontado com as Badaladas. Quando às internas, são as encontradas nas próprias crônicas, tais como citações e determinados recursos estilísticos. A leitura contínua das Badaladas e o seu exame comprovaram terem sido escritas pelo mesmo autor. A repetição de temas, referências culturais e literárias e citações no restante da obra machadiana e a congruência da escrita das Badaladas com fatos biográficos comprovaram a autoria. Ao final de cada ano, apresentam-se tabelas com as marcas comprobatórias dessa autoria, crônica por crônica. No ensaio introdutório, Sílvia Azevedo aborda alguns dos temas privilegiados pelas Badaladas.

Com a garantia de que se tem nas mãos uma obra machadiana, reconhece-se o humour, a ironia, a surpreendente associação de ideias, o gosto pelo paradoxo, a erudição e principalmente o espírito crítico que costumamos atribuir a Machado de Assis. Assim como o romancista de $A$ mão e a luva, Dr. Semana zomba de poetastros, denuncia a vacuidade de determinados discursadores, inclusive políticos, e vasculha os jornais da Corte, das províncias e até do exterior em busca de notícias e anúncios extravagantes sobre os quais pudesse exercitar a sua verve. Em se tratando de Machado, a quem se atribui o famoso tédio à controvérsia, espanta na série das Badaladas o modo corajoso e sempre vigilante por que se enfrentam os descaminhos e arbítrios de uma parte do clero, diligentemente defendida pelo jornal $O$ Apóstolo. O ultramontanismo dessa publicação era 
abertamente combatido pelo Dr. Semana, que se amparava em princípios etimologicamente republicanos e, em vários casos, cristãos, por paradoxal que pareça.

Assim como muitos contemporâneos, Machado de Assis provavelmente não valorizava todos os textos que publicava na imprensa por julgá-los efêmeros como os veículos que os acolhiam. Em algumas Badaladas, vislumbramos, com efeito, o esforço do cronista, profissional da imprensa periódica, por encontrar um assunto qualquer que pudesse ocupar as páginas cativas da Semana Ilustrada. É o caso, salvo melhor juízo, das “Escavações históricas por um Quidam”, nas quais se apontavam falsas origens históricas de determinados vocábulos. Eram empulhação, conscientemente escritas como empulhação, graças à licença do humor, e provavelmente apreciadas pelos contemporâneos como saborosa empulhação. No jornalismo, pratica-se até hoje uma arte da empulhação, que, no entanto, não está ao alcance de qualquer foliculário. Há, porém, nos dois volumes, páginas de grande interesse, como a crônica de 12 de julho de 1874, uma paródia do Inferno, identificada como "Canto suplementar ao poema de Dante pelo Dr. Semana” (ASSIS, 2019, v. 2, p. 327-331). Machado de Assis simplesmente acrescenta um novo círculo ao inferno, dedicado aos fâmulos (criados domésticos).

Outra publicação machadiana recente que atrai a atenção é um trabalho crítico que põe ênfase justamente no forte e continuado vínculo de Machado de Assis com a imprensa periódica. Trata-se de Machado de Assis - antes do livro, o jornal, de Lúcia Granja, obra integralmente disponível para download no site da editora Unesp.

Baseando-se em bibliografia recente, especialmente em trabalhos de Marie-Ève Thérenty, Allain Vaillant e Dominique Kalifa, Lúcia Granja parte do princípio de que há uma poética do jornal, isto é, o veículo, entendido como suporte material, condiciona a literatura nele produzida. Segundo Thérenty, a escrita jornalística resulta de duas matrizes distintas, a jornalística e a literária. Sendo muitos jornalistas do século XIX também escritores, levaram para o periódico cotidiano recursos literários como a ficcionalização, a ironia, ritmo e estrutura de conversação e escrita íntima (centrada no eu do escritor/jornalista). Os jornais, porém, também impunham quatro regras principais para a escrita, limitando o arbítrio de seus colaboradores: 1) a periodicidade, pois o exercício de escritura era 
forçosamente renovado a intervalos regulares, ou seja, diários, semanários ou mensais, conforme a modalidade de periódico; 2) a atualidade, em virtude do compromisso do jornalismo com o tempo presente; 3) o efeitorubrica, isto é, a necessidade do jornalista conformar-se a uma especialidade, recortando do mundo prioritariamente o que dissesse respeito à sua rubrica; 4) a coletividade, ou seja, o imperativo de ajustar-se a um trabalho de natureza coletiva e à interdependência das rubricas que compõem o mosaico do jornal. A combinação das duas matrizes no interior do jornal acabou por dar origem a gêneros jornalísticos modernos como crônica, reportagem, fait-divers e entrevista.

Na década de 1980, Marlyse Meyer já refletira sobre a importância do trabalho desenvolvido por escritores para o periodismo antes mesmo do nascimento de Machado de Assis:

Pode-se dizer [...] que traduzir $O$ folhetim, traduzir folhetinsvariedades, publicar romance em folhetim, e escrever nos folhetins, ${ }^{1}$ constitui para os jovens brasileiros candidatos a escritores no primeiro terço do século XIX um verdadeiro laboratório, no sentido em que hoje se diz dos atores de teatro que fazem laboratório.

E entre as experiências bem-sucedidas desse laboratório está a conquista de uma linguagem solta, de grande alacridade, que, se não elimina uma também cabocla impostação oratória, dá a certas partes do jornal um tom que sabe a frutinha brasileira, de pitanga ou araçá. (MEYER, 1985, p. 39).

O livro de Lúcia Granja aprofunda essa percepção geral ao examinar a possibilidade de que a peculiaridade ou "monstruosidade" de Machado de Assis resultasse de uma longa e completa imersão no jornalismo, tornada agora ainda mais evidente com o trabalho de Sílvia Azevedo, o qual nos mostra o romancista como ativo praticante do jornalismo em geral e da crônica em particular no período de 1869 a 1876. Levando-se em consideração o trabalho na Semana Ilustrada, pode-se dizer que o criador de Brás Cubas esteve quase ininterruptamente vinculado ao jornalismo por 36 anos, contados dos "Comentários da semana", publicados a partir de 1861 no Diário do Rio de Janeiro, até “A Semana”, da Gazeta de Notícias, encerrada em 1897.

\footnotetext{
${ }^{1}$ Folhetins-variedades e folhetins tout court eram designações aplicáveis à crônica.
} 
Segundo a tese apresentada por Lúcia Granja, forjou-se a escrita machadiana no exercício do jornalismo, mediante a exploração dos efeitos ambíguos da contiguidade e proximidade dos textos no mosaico do periódico e através do estabelecimento de diálogos com outros jornalistas de outros veículos. Assim como diretores de jornais mais lúcidos, Machado de Assis seria hábil em suscitar efeitos de polifonia e contraponto de seus textos com os alheios. As citações e referências eram sacadas de um pecúlio comum, às vezes representado pelos catálogos das livrarias em vigor. Nas crônicas, os fragmentos eram justapostos de forma arbitrária e segundo caprichosas e paradoxais associações de ideias do cronista, por vezes transformado em personagem como o Dr. Semana. As diferenças entre as versões publicadas de forma seriada e as publicadas em volumes, notáveis nos casos de narrativas como Memórias póstumas de Brás Cubas e Quincas Borba, revelavam a apurada consciência, da parte de Machado de Assis, a respeito dos recursos e condicionamentos associados aos veículos e à materialidade de cada modalidade de produção editorial. Lúcia Granja assim resume como compreende a contribuição do periodismo para a formação de Machado de Assis:

Fixado aos periódicos por características do seu tempo, o escritor aproveitou as formas dos jornais e revistas (plasticidade da página, circulação entre os textos, escala entre a ficção e a referencialidade), assim como as adaptações brasileiras dadas à publicação periódica (maior elasticidade, coabitação de diferentes formas no mesmo espaço, modificações no corte do romance-folhetim, intensificações advindas da plasticidade) em sua própria criação literária, aludindo ou parodiando todas essas novidades. (GRANJA, 2018, p. 102).

A tese é pertinente e joga uma nova luz sobre o processo de formação do escritor Machado de Assis. De fato, parece muito adequado afirmar, graças à leitura das obras aqui resenhadas, que sua escrita não foi forjada no isolamento de uma torre de marfim, mas no ambiente dinâmico e nervoso das redações de periódicos, sempre atentas às dores do mundo e aos pensamentos e anseios dos contemporâneos. Caso se recordassem outros trabalhos das próprias Sílvia Azevedo e Lúcia Granja, os quais por sua vez se associavam aos de John Gledson e Sidney Chalhoub, entre outros, talvez fosse possível afirmar que, para pelo menos parte da geração atual, Machado de Assis foi, essencialmente, um infatigável, lúcido e originalíssimo colaborador da imprensa periódica, terreno fértil onde brotou parte significativa de sua obra. 


\section{Referências}

ASSIS, J. M. Machado de. Badaladas Dr. Semana. Organização, apresentação, notas e índice onomástico por Sílvia Maria Azevedo. São Paulo: Nankin, 2019. 2 t.

CANDIDO, Antonio. Vários escritos. 2. ed. São Paulo: Duas Cidades, 1977. GRANJA, Lúcia. Machado de Assis - antes do livro, ojornal: suporte, mídia e ficção. São Paulo: Editora Unesp, 2018.

MEYER, Marlyse. Voláteis e versáteis, de variedades e folhetins se fez a chronica. Boletim Bibliográfico Biblioteca Mário de Andrade, São Paulo, v. 46, n. 1-4, p. 17-42, 1985.

Recebido em: 19 de março de 2020.

Aprovado em: 06 de julho de 2020. 